\title{
Discussion on Opportunities, Challenges and Countermeasures Faced by China's Development of Low-carbon Economy
}

\author{
Xudong $\mathrm{Li}^{1}$, Jin $\mathrm{Xie}^{2}$ \\ ${ }^{1}$ Chongqing University of Science and Technology, Chongqing 401331, China \\ ${ }^{2}$ Chongqing City Management College, Chongqing 401331, China
}

\begin{abstract}
Keywords: Low-carbon economy, Opportunities, Challenges, Green economy, Sustainable development.
\end{abstract}

\begin{abstract}
Today, global warming has become necessary to human survival and development issues, in the face of worsening global warming, reduce carbon emissions substances, the development of low-carbon economy, has become the general trend of economic development of countries. For its part, the international situation at the premise of competition is so fierce, the development of low power consumption, is characterized by "low-carbon economy," there will be some opportunities and unprecedented challenges. Faced with this environment, a detailed analysis of the current situation to the development of low-carbon technologies and technological innovation a combination of low-carbon economy, increase efforts to implement energy conservation, recycling economic policies, will give top priority to sustainable development, renewable reuse a lot of energy and clean energy development.
\end{abstract}

\section{Definition and development status of low-carbon economy}

\section{Definitions of low-carbon economy.}

The so-called low-carbon economy means: the basis of sustainable development, through technological innovation, system innovation, industrial restructuring, new energy development and other means to minimize the carbonaceous material consumption, reduce greenhouse gas emissions, to achieve social economic and ecological balance of a win-win result.

Low-carbon economy to reduce greenhouse gas emissions for the purpose of constituting the low pollution, low energy consumption economic development system, comprising: a low-carbon energy, low-carbon technologies and low-carbon industrial system. Three systems from reducing coal, oil and other fossil energy use, development of new energy sources, recycling started, achieve energy conservation, zero pollution indicators work.

"Low-carbon economy" was first to see government documents in 2003 UK Energy White Paper "Our energy future: Creating a low-carbon economy." For Britain, the advocator of first industrial revolution and an island country which resources are not rich, it was fully aware of the face of climate changes and energy security threats. For the vast territory and large population of the country side, the low-carbon economy now, is imminent.

\section{Development status.}

Many of the industrial revolutions, many people create material wealth, the world economy has been fully developed, but, at the same time, the environment is also a severe deterioration of various survival on Earth is becoming more and more acute. If we continue to develop the economy on the basis of damage to the environment, so in the near future, people have to pay a bitter price for their actions. In recent years, the frequent occurrence of natural disasters around the world, which has been warning humanity is to start protecting the survival of our homeland. To deal with such situation, low-carbon life has become the world everyone's responsibility and obligation.

Scientific research shows that global warming is due to excessive gas emissions of greenhouse gases caused by humans. Faced with this conclusion, a number of countries and researchers began to reflect on social development and improvement, the "low-carbon life", "low carbon economy", "low carbon society" and "low-carbon development" and the widespread production and life and liaise powers, bound together to achieve common low-carbon economy. 
Faced with this scenario, China has also outdone, made a number of unique insights for the development of low-carbon economy. Chinese leaders in the major report stressed that "building socialism with Chinese characteristics at the same time, the market economy, democratic politics and advanced culture combine to adhere to sustainable development strategy and achieve a low-carbon social and economic development. This requires that we to adhere to the national policy of conserving resources and protecting the environment, and vigorously implement green development, low-carbon development and development cycle, improve production and living, industrial structure, and spatial distribution pattern, the trend of ecological deterioration of the fundamental solution to the State to the national policy strong support for new energy development and utilization and measures of energy conservation, recycling economy will penetrate into people production and living, so that resources can be reused. Therefore, vigorously promote low-carbon life, for the sustainable development of the international economy, as well as multiple use of resources, there is an indelible role of low-carbon economy is the social civilization, health, harmonious development of the fundamental, is the trend.

\section{Opportunities, challenges and countermeasures faced by development of low-carbon economy}

\section{Opportunities.}

1) Strategic opportunities brought by economic globalization

As the third industrial revolution, the major international economic development shows the trend of economic globalization, the various economic powers led by the US you have me, I have you, this situation is the arrival of an unprecedented economic development impact. With the increasing popularity of low-carbon economy, the world economy is undergoing profound changes, especially in the new energy, a tremendous impact. Despite the development of new energy and Western countries technically have a certain gap, but as long as we are caught in the wave of economic globalization opportunities through institutional reform in the process, optimize the industrial structure, as far as possible in the short time to catch up, low-carbon economy to achieve the ultimate.

2) Market opportunities brought by low-carbon products and system innovation

Now, advocating low-carbon economy to make low-carbon products in the production process, constantly being changed and innovation, which is to improve low-carbon economy, low carbon economy offers to solve the emerging markets, there is an important role. Accelerate innovative market economy, will undoubtedly provide an unprecedented opportunity for innovation of low-carbon products.

The "Kyoto Protocol" for certified emission reductions explicitly defines industrialized countries to achieve emission reduction targets at a lower cost. In the Clean Development Mechanism, developing a low carbon economy can be obtained funds. For our part, as the clean development mechanism (CDM) development of beneficiary countries, according to the Convention on Climate Change Secretariat statistics, China is the largest country in the implementation of CDM projects in low-carbon treatment, the most expensive, so that Chinese economy has been severely affected . In addition, the CDM is not only the capital of the acquired channels, more important is the effective model of energy conservation. Therefore, optimization, improve the structure of foreign investment, is significant. Global demand for renewable energy development and utilization is constantly exploring the current discovery, a huge amount of investment. As a developing country, China should find this opportunity to take advantage of current technology, the development of new and renewable energy sources and gradually replace fossil energy sources, promote the process of development of new energy, opening a milestone on the other side belong to China, and the world.

3) Latecomer opportunities brought about by the development of low-carbon industries

Low-carbon economy including: renewable energy and energy saving technology. Today, our country will be wind, solar, hydro, biomass and other clean energy used in production and life, with a huge influence. According to the 2010 summit in London, New Energy Finance data show that China's clean energy growth rate of living in the world, the development of solar, biomass, nuclear and other new energy rapid rise. While many of China's new energy development, but very little real use efficiency, far lower than the international level, which requires the country to improve the 
utilization of new energy. Thus, the prospect of China's low-carbon economy is very impressive, with a huge market potential.

\section{Challenges.}

Today, China is in the primary stage of socialism's economic development, economic development directly affects China's modernization, including low-carbon economy, especially significant. Although the low-carbon economy provides an opportunity for China, also it brings challenges for China.

1) Rapid economic growth in the traditional environment of negative external pressure

China is in the development stage of industrialization, rapid urbanization, changing the energy of the national economy which supports high-speed run, this significant investment growth funds, although our country's rapid economic development, but at the same time also damaged the environment, for our country He paid a terrible price. Therefore, for this contradiction, how to release negative environment external pressure to open up low consumption, low emissions a part of China, the development of clean and efficient road low-carbon economy, the challenges facing our country.

2) Actual challenges brought by China's resources characteristics

Our geographical location makes our resources with the "oil-poor little rich coal gas" features. Traditional fossil energy sources, low utilization rate, and serious pollution, make our resources on difficult reforms. This phenomenon requires that we can not rest on its laurels, requires a highly developed low-carbon economy, the development of new energy sources. Faced with such competitive pressures in Western countries will not be repeated expense of the environment and the environment of his country under the premise of their own country, the development of low-carbon economy, the reality is that China must face the challenge.

3) Economic policies of developed countries, China's export products are increasingly squeezed by external

As a big country of global carbon emissions, our country is destined to be squeezed from various countries for some time in a low-carbon economy. On the one hand, the developed countries in the hope of a positive attitude towards the development of low-carbon economy, the use of some means to force China to carry out development policies do not meet China's national conditions. On the other hand, financial and technical requirements for China to make some commitments do not meet even unrealistic, which is China's low carbon economy, enormous pressure.

In addition, China as a manufacturing country in the world has a "world factory" status. But because our country is at the bottom of the world's manufacturing, for contributing to the economy, we had to leave the pollution generated in the country. With such a low-carbon economy will be, our country is facing a highly difficult, not to lower the status of development of the market so that trade is affected. High developed countries to enable developing countries to introduce them to a low-carbon economy, new technologies, so that their products sold overseas, seek violence. This behavior is the same height, but the press in developing countries such as China, the economy severely marginalized.

\section{Countermeasures.}

Since the new century, global warming is getting worse, countries have launched intense discussions to a low-carbon economy as the main direction. For my country, low-carbon economy from reality, the implementation of the sustainable development strategy, firmly opposed to developing countries deal with historical issues in developed countries. So, it requires us at the same time economic construction, the time to implement the scientific concept of development, while protecting the environment, economic development, the formation of green economic development.

1) Vigorously develop renewable energy and promote low-carbon energy mix

China's economic development has always been to rely on fossil fuels, wind, hydro, solar and other clean energy has just started, but in the long perspective, the policy benefits the country and low-carbon economy. Thus, effectively optimize China's energy structure, development of renewable energy, actively support the development of clean energy and the direction of new layouts to change the status quo of high-carbon economy at the roots. 
2) Vigorously develop the circular route, improving heat efficiency. Reduce carbon emissions

Characteristics and level of economic development of the country's resources, determine our country in the future for a long period of time is difficult to change the status quo in the energy of fossil fuels as the main energy. Thus, we should be based on actual, improve the utilization of fossil fuels, efforts in the economic cycle, increased energy use, reduce carbon emissions, which is an economic model of economic development, environment, nature combined with each other. At present, China in the implementation of various regions within the business cycle, and the cycle industry chain loop region, and achieved gratifying results, worthy of promotion.

3) Strengthen technological and institutional innovation in low-carbon economy

Low-carbon technologies can maximize energy savings, reduce the production of greenhouse gases. Development of innovative low-carbon technologies, conducive to the development of new energy sources, and carbon dioxide in the atmosphere will be treated being discharged from the carbon emissions to a minimum. Low-carbon technology R \& D and innovation, to achieve carbon emissions "zero emissions" have a positive effect. Therefore, China should strengthen the independent innovation capability, enhance the level of low-carbon technologies, and actively cooperate with developed countries, the development of clean development mechanism, efforts to promote the recognition of our low-carbon economy in developed countries, so that low-carbon technologies for acceptance and absorption.

\section{Results}

Development of low-carbon life in today's society is the fundamental development of the country, for our country in terms of opportunities and challenges exist and height. However, the development of low-carbon economy to provide for the fundamental change in the way our economic opportunity, low carbon road, is to deal with global warming is now a fundamental way, is also the root cause of sustainable development practice where, low-carbon economy favorable change China's economy to the environment coexist bottlenecks and take the road of industrialization with Chinese characteristics. This undertaking is conducive to world economic trends, the improvement of low-carbon economic development policy and security system is conducive to promoting China's domestic economy, enhance China's international competitiveness, help to change the world of global warming in the process, while for establishing the image of our country in the world has a positive environmental effect.

Low-carbon economy for life on Earth, especially the endangered creatures is undoubtedly the most effective protection policy. In addition, for us humans, it is also an effective measure can protect the lives of future generations. This is our country and the world is worth advocating economic policies.

\section{Conclusions}

Road Chinese low-carbon economy, we must strive for more development rights, to meet people's material needs, but also to improve conservation and green consumption, not according to Western consumption standards, to meet the growing consumption patterns. This is mainly because either the resources or the energy point of view, the Western consumer do not meet China's national conditions, China is not suitable for Western luxury consumption, which means that China can not copy the Western experience.

China today, in science and technology is more developed, but also more complex environment. Whether it is from the location, or from the population, the average of the economy is still at a disadvantage relative to developed status. As a developing country, economic production emissions of pollutants remain a daunting task. China's low-carbon economy must proceed from the actual situation in China, not to others, and in conjunction with China's national conditions, to go their own way of low-carbon economic development of character. But based on our country roads, low-carbon economy is destined to not be smooth, that we need a new generation of workers fought to solve the 
current problems faced, and constantly develop new technologies, provide new energy, recycling, sustainable development, will be low carbon economy onto the top of the Chinese economy.

\section{Acknowledgments}

This paper is humanistic and social science study project of Chongiqng Education Committee in 2015, NO.: 15KSG187.

\section{References}

[1] Wang Ximing, An Tielei. Opportunities, challenges and countermeasure faced by China's development of low-carbon economy, Journal of Socialist Theory Guide, 2013,37(09) : 99-101.

[2] Xin Junyi. On problems faced by China's development of low-carbon economy and their countermeasures, Chinese Urban Economy, 2010,11(12):90-91.

[3] Yang Guang, Wen Bo. Development of low-carbon energy pathway analysis and recommendations, China Business Upate.2011,18(5):80-82. 